\title{
Surgical treatment of hydatid cyst of the lung: review of 30 cases
}

\author{
i. Yalçinkaya*, M. Er*, B. Özbay**, S. Uğraş***
}

Surgical treatment of hydatid cyst of the lung: review of 30 cases. I. Yalçinkaya, M. Er, B. Özbay, S. Ugras. ERS Journals Ltd 1999.

ABSTRACT: Hydatid cyst disease is still a problem in Turkey, especially in the east Anatolian region, as well as in many other places in the world. A retrospective review was made of the surgical treatment of $\mathbf{3 0}$ patients with pulmonary hydatid cysts during the last 3 yrs.

Nineteen patients were male and 11 female with an average age of 23.5 yrs (range 444 yrs). Cystotomy and capitonnage were performed in 28 of the 30 cases $(93.4 \%)$. The transdiaphragmatic route or simultaneous laparotomy was preferred when the liver was involved. Albendazole was used in four patients with multiple hydatid cyst due to probable recurrence in the postoperative period.

Cough and chest pain were the prominent symptoms in the majority of cases. A single lobe was affected in 22 patients. Unilateral multiple foci were present in four patients and bilateral multiple foci in four. Six patients had concomitant liver cysts. Morbidity was low and no mortality was seen. No recurrences were seen on control chest radiographs during the last 2-yr follow-up.

In the treatment of hydatid cyst of the lung, conservative surgical methods such as cystotomy and capitonnage still remain the treatment of choice. Medical treatment could be used for prophylactic purposes and in some instances, but the percutaneous aspiration method should not be performed.

Eur Respir J 1999; 13: 441-444.
Depts of *Thoracic Surgery, **Chest Diseases and ****athology, School of Medicine, Yüzüncü Yil University, Van, Turkey

Correspondence: î. Yalçinkaya

Tip Fakültesi Hastanesi

Gögüs Cerrahisi Klinigi

65300 Van

Turkey

Fax: 904322167519

Keywords: Hydatid disease

lung

surgery

Received: June 251998

Accepted after revision October 81998
Hydatid disease, caused by Echinococcus granulosus, is endemic in the Mediterranean region, South America, Australia and New Zealand [1-4]. Turkey is located among the Balkans, Caucasia and the Middle East, which bridges Asia and Europe and, owing to its geographical situation, is affected by the endemic diseases in the region $[5,6]$. In addition to cattle breeding and agricultural factors, uncontrolled sacrifice of cattle for religious reasons in Turkey poses a great risk. Hydatid disease of the lung is still a major problem in rural areas where cattle breeding and agriculture are the main sources of living. In Turkey $60-87 \%$ of cases come from rural areas [3]. This study reports on 3 yrs of experience of the surgical management of 30 cases with pulmonary hydatidosis.

\section{Materials and methods}

A retrospective review was made of 30 cases with pulmonary hydatid cysts who were treated surgically in the Department of Thoracic Surgery, Yüzüncü Yil University, School of Medicine, between March 1995 and March 1998. Nineteen male and 11 female patients, whose ages ranged 4-44 yrs, with an average of $23.5 \mathrm{yrs}$, participated in the study (table 1).

Twenty-five patients, all from the rural population, with common symptoms such as cough and chest pain and a history of contact with dogs presented at the clinic. One patient had undergone a previous operation at another institution for a pulmonary hydatid cyst.
Table 1. - Patient characteristics

\begin{tabular}{lccc}
\hline $\begin{array}{l}\text { Age range } \\
\text { yrs }\end{array}$ & $\begin{array}{c}\text { Female } \\
\mathrm{n}\end{array}$ & $\begin{array}{c}\text { Male } \\
\mathrm{n}\end{array}$ & $\begin{array}{c}\text { Total } \\
\mathrm{n}\end{array}$ \\
\hline $0-9$ & 1 & 2 & 3 \\
$10-19$ & 3 & 5 & 8 \\
$20-29$ & 2 & 3 & 5 \\
$30-39$ & 4 & 7 & 11 \\
$\geq 40$ & 1 & 2 & 3 \\
Total & 11 & 19 & 30 \\
\hline
\end{tabular}

The diagnosis was established through routine chest radiography and ultrasonography (thoracic and/or abdominal). Thoracic computed tomography (CT) scans were also used in the diagnosis of two cases (fig. 1). Dermal tests, complementary fixation tests and indirect haemagglutination were not used.

All operations were performed under general anaesthesia via a posterolateral thoracotomy approach. Thoracotomy, preserving the serratus anterior muscle, was performed in one child. The four patients with bilateral disease were managed with staged thoracotomies (after an interval of 1 month); thus, 34 operations were performed on 30 patients (table 2). Cystotomy and capitonnage, the preferred techniques, were carried out in 28 (93.4\%) patients. Capitonnage was not used in two patients because the cyst was very large and had not been properly localized anatomically; this could have caused postoperative atelectasis. Four patients underwent hepatic intervention after thoracotomy via the transdiaphragmatic route. In 


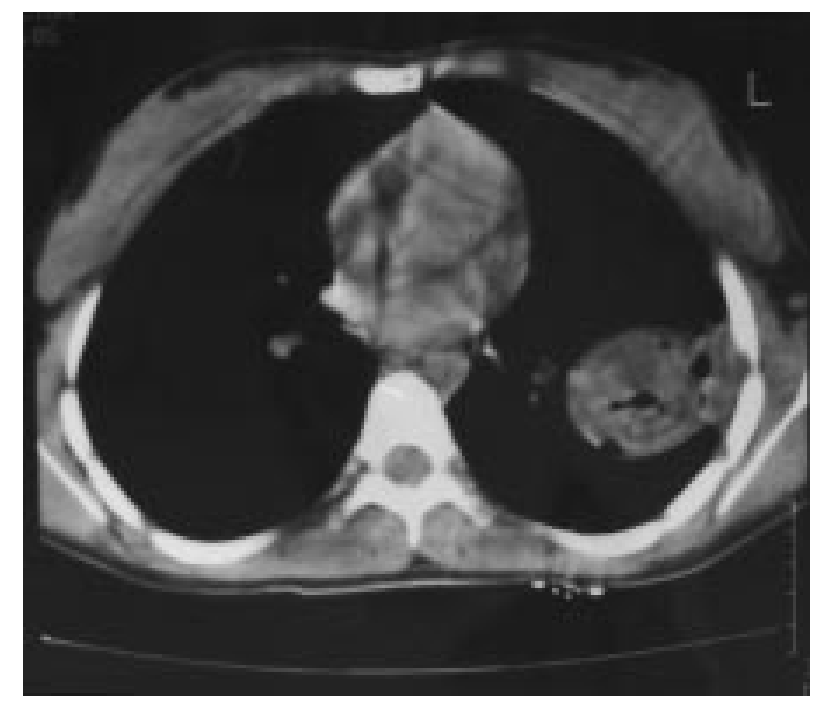

Fig. 1. - A mass lesion in the left lower lobe on the computed tomographic scan (perforated hydatid cyst).

three patients with liver cysts, cystotomy and capitonnage were performed. Indwelling tube drainage was used in the other patient, who had a subdiaphragmatically placed tube drain retained until there was complete closure of the residual cavity. In the remaining two patients, cystotomy and capitonnage were applied via median laparotomy simultaneously. Two patients who had thick pleura were decorticated, in addition to cystotomy and capitonnage.

\section{Surgical technique}

Posterolateral thoracotomy through the fifth, sixth or seventh intercostal space was accomplished with the patient in the lateral decubitus position. The thoracotomy wound and the lung, apart from the area containing the cyst, were covered with sponges moistened with $1 \%$ povidone-iodine to prevent inadvertent implantation of scoleces or daughter cysts. With needle aspiration, hydatid fluid was aspirated from the uppermost part of the cyst to lower the intracystic pressure. Then, a suction apparatus was introduced into the cyst and the fluid was completely aspirated. No scolicidal agent was used. In all patients, the needle and suction apparatus insertion site were enlarged by cutting the pericystic layer (host tissue) with an electrocautery so that the germinative membrane was easily taken out and the bronchial cystic cavity exposed. In the cysts

Table 2. - Surgical methods

\begin{tabular}{lc}
\hline Procedure & $\begin{array}{c}\text { Patients } \\
\mathrm{n}\end{array}$ \\
\hline Lung & 28 \\
Cystotomy and capitonnage & 2 \\
Cystotomy without capitonnage & \\
Liver & 3 \\
Cystotomy and capitonnage & 2 \\
transdiaphragmatically & \\
by laparatomy & 1 \\
Tube drainage & \\
transdiaphragmatically & \\
\hline
\end{tabular}

with a small pericystic layer and a deep residual cavity, this layer was removed only minimally (cystotomy), whereas the cysts with a large pericystic layer and superficial residual cavity underwent extensive resection. After the removal of the germinative layer, the residual cavity was carefully cleaned by a suction apparatus and irrigated with $1 \%$ povidone-iodine in all patients. When the cystic cavity was being obliterated, large bronchial cavities were first closed with a 3-0-coated vicryl (polyglactin 910). Then, the cavity was obliterated by purse-string sutures using the same suture material (capitonnage).

All cysts were subjected to histopathological examination, which confirmed the diagnosis.

\section{Results}

Table 3 shows the distribution of the cysts in various lobes. A single lobe was affected in 22 patients. Unilateral multiple foci were present in four patients and bilateral multiple foci in three (fig. 2). A total of 45 cysts were found in 30 patients. Of these 40 cysts, 22 were intact and uncomplicated. Eleven cysts were both ruptured and infected and 12 cysts were ruptured only. Three patients had giant pulmonary hydatid cysts, which were $\geq 10 \mathrm{~cm}$ diameter (fig. 3). The remaining three cysts had complications (hydropneumothorax). One patient was admitted to the emergency unit with tension pneumothorax. In six patients there were concomitant liver cysts.

Postoperative complications were infrequent and no mortality was seen. Wound infections developed in two cases and resolved with local treatment. Prolonged parenchymal air leak ( $>5$ days) was observed in four patients and was managed by continuous negative aspiration. Pneumothorax occurred in two cases, but the lung re-expanded following thoracostomy closure. Atelectasis developed in two cases and resolved through bronchoscopic aspiration.

Albendazole $\left(10 \mathrm{mg} \cdot \mathrm{kg}^{-1}\right)$ was administered daily for 4 weeks following the operation for prophylaxis in four cases (one patient with unilateral lung plus liver cysts; three patients with bilateral lung plus liver cysts).

No recurrences were seen on control chest radiography during 3 yrs of follow-up.

\section{Discussion}

Intact or simple hydatid cysts of the lung have no characteristic symptoms. Their clinical manifestations de-

Table 3. - Location of hydatid cysts ${ }^{\dagger}$

\begin{tabular}{lc}
\hline Location & $\begin{array}{c}\text { Patients } \\
\mathrm{n}\end{array}$ \\
\hline Single lobe & 22 \\
Right upper lobe & 5 \\
Right middle lobe & 5 \\
Right lower lobe & 5 \\
Left upper lobe & 3 \\
Left lower lobe & 4 \\
Unilateral multiple foci & 4 \\
Bilateral multiple foci & 4 \\
\hline : In six cases hydatid cysts were also present in extrapulmonary \\
organs (six liver cysts).
\end{tabular}




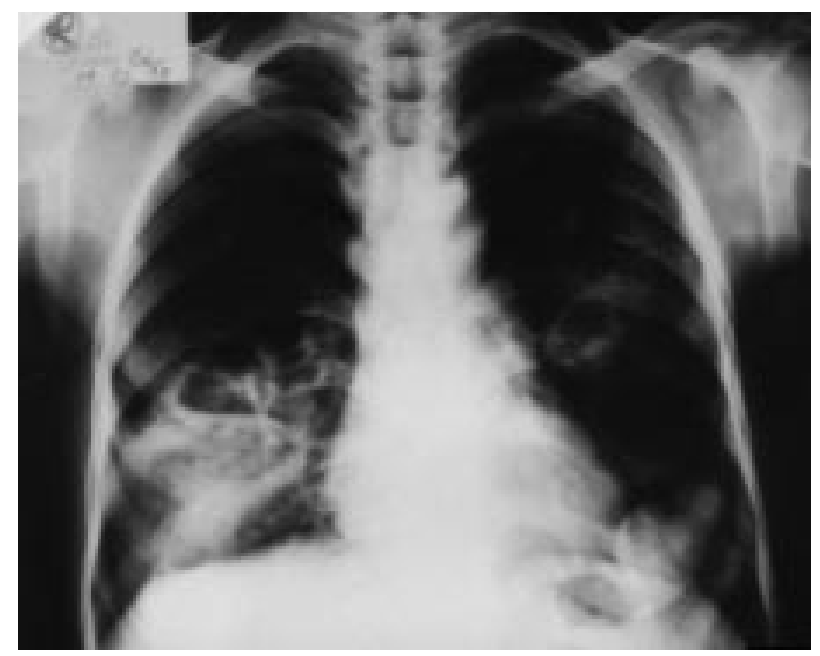

Fig. 2. - Bilateral multiple perforated and nonperforated hydatid cysts on the chest radiograph.

pend on the site and size of the cyst. The diagnosis of an intact hydatid cyst is usually based on a suspicion resulting from an unexpected finding on routine chest radiographs. Radiography allowed an accurate diagnosis in $93.4 \%$ of cases. Currently, the CT scan provides the most accurate findings. Dermal tests, complementary fixation tests and indirect haemagglutination tests can be used for diagnostic purposes $[3,4]$.

Hydatid cysts can be located in various tissues, although they are usually seen in liver and the lung [7]. Pulmonary hydatid cysts can be located in any pulmonary lobe and consist of multiple foci in one or both lungs. The right lower lobe is the most frequently attacked area of the lung, as seen in a review of the literature $[1,3,4]$. In the cases reviewed here, localization of the right lobe was more frequent than the left.

Response to medical treatment (e.g. mebendazole, albendazole) is apparently related to the thickness of the

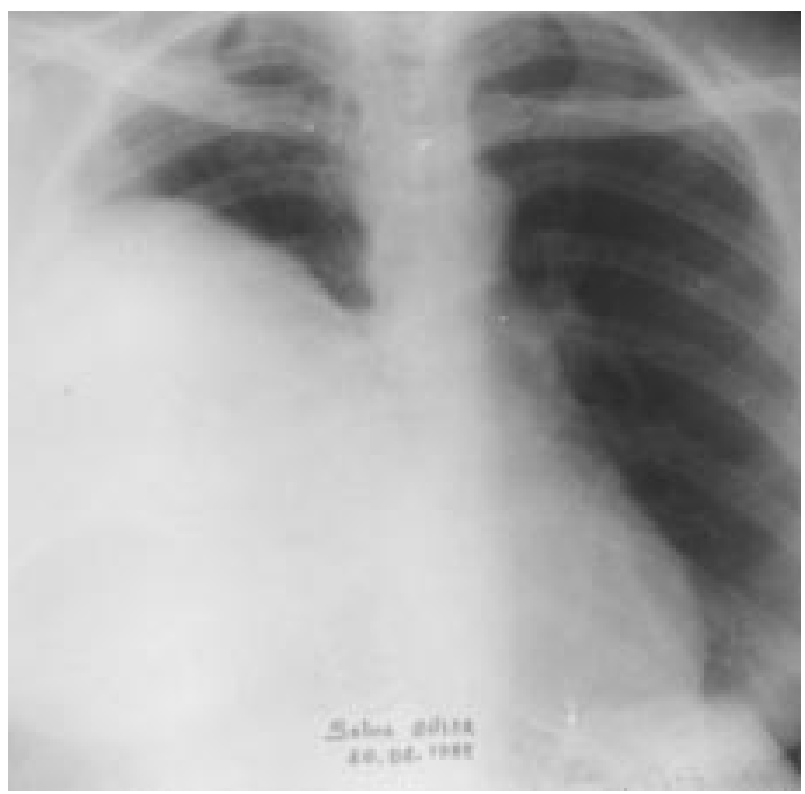

Fig. 3. - Giant hydatid cyst in the right lung on the chest radiograph. cyst wall, which the drug must penetrate to reach the germinal layer. The failure rate of this therapy and the recurrence rate after the treatment is discontinued are apparently high. As a result, until more data are available, this form of treatment can be applied in selected cases under close observation, and is mainly recommended for inoperable cysts because of dissemination or contra-indication for surgery $[6,8]$. Medical therapy was not applied routinely, but only for four cases with multiple lung plus liver hydatid cysts, to prevent the possibility of a relapse. Albendazole was preferred to mebendazole, considering its high cost, shorter treatment period, efficiency in lower doses and fewer side-effects.

When benzimidazole compounds were used preoperatively, even when the parasite in the lung died, the membranes were retained and the patient needed an operation because of recurrent infection. Germinative membranes in the cysts were observed to liquefy in a patient who underwent surgical removal of multiple hydatid cysts of the left lung, administered albendazole and had recurrent infection. Recent reports also indicate that others have found that chemotherapy alone is not reliable in controlling E. granulosus disease [9].

Studies on the application of the PAIR (puncture, aspiration of cyst contents, injections of hypertonic saline solution, reaspiration) method in pulmonary hydatid cysts, which is used mainly in hepatic hydatidosis, are insufficient, with limited patient numbers, and have shown more severe complications than methods used for other organ cysts [10].

Although recent reports suggest medical therapy with albendazole and percutaneous treatment, surgery is still the best choice for treatment of hydatid disease [11]. Surgical operation, which should be performed soon after diagnosis to prevent complications such as cyst rupture or infection, is the principal method of treatment. The current treatment of hydatid cyst of the lung is complete excision of the disease process with maximum preservation of the lung tissue. Most authors advocate conservation of the lung parenchyma, reserving resections for ruptured cysts that result from destruction or infection of the adjacent tissue [4]. Various surgical procedures have been described in the literature [1-3]. The criteria for selecting operative techniques differ from one country to another. In countries where the disease is endemic, e.g. Turkey, resection should be avoided as far as possible, because the disease may recur even in operated patients. Therefore, the authors prefer conservative surgical methods that do not lead to tissue loss; neither enucleation (the Ugon method) nor cystectomy (the Perez-Fontana method) was performed. The authors do not advocate enucleation because of the higher risk of contamination and cystectomy because it increases the risk of air leaks and postoperative bleeding. Cystotomy and capitonnage of the residual cavity are the methods of choice in the authors' clinic.

Most surgeons use $1 \%$ formaldehyde or hypertonic saline solution for deactivation of cysts and protection of the operative field [4]. Formaldehyde has a necrotizing effect since it penetrates the lung parenchyma through air leaks around the cyst. Povidone-iodine 1\% was used since it helps to prevent recurrence as a scolicidal agent, like a hypertonic saline solution, and acts as an antibacterial agent. 
Every patient who has hydatid cysts of the lung should be investigated for associated cysts in the liver. Many liver cysts can be approached from a thoracic route after incising the diaphragm, as in four of these patients [9]. In two patients, localization of liver cysts did not allow a transthoracic approach; therefore, laparotomy was performed simultaneously following thoracotomy to avoid the potential risks of a repeated general anaesthesia.

When bilateral cysts are present, some surgeons prefer a one-stage operation via a median sternotomy and this method is applicable when bilateral lung and liver cysts are present [11]. A two-stage thoracotomy was preferred by the authors, operating on the side with the larger, ruptured and infected cyst first. However, median sternotomy is a better alternative for the treatment of bilateral hydatid disease of the lung. This method is more economical, causes less pain and is better tolerated than two thoracotomies [12].

Incidences of recurrence of $2-12 \%$ have been reported in the literature [13]. No recurrences were seen during the mean 2 yrs of follow-up in the present study.

In summary, the prevention of hydatidosis is more important than treatment in countries where the disease is endemic. Medical treatment may be applied in inoperable cases or after surgery to avoid a relapse as an adjunctive therapy. Surgery is the treatment of choice for pulmonary hydatid cysts. Conservative surgical methods that preserve lung parenchyma are usually preferred. However, simultaneous surgical approaches involving two or three organs may be preferred owing to lower mortality and morbidity rates and hospitalization time.

\section{References}

1. Ayuso LA, Tellez de Peralta G, Lazaro RB, Stein AJ, Sanchez JA, Aymerich DF. Surgical treatment of pulmonary hydatidosis. J Thorac Cardiovasc Surg 1981; 82: $569-575$.
2. Novick RJ, Tchervenkow Cl, Wilson JA, Munro DD, Mulder DS. Surgery for thoracic hydatid disease: a North American experience. Ann Thorac Surg 1987; 43: 681686.

3. Dogan R, Yüksel M, Çetin G, et al. Surgical treatment of hydatid cysts of the lung: report on 1055 patients. Thorax 1989; 44: 192-199.

4. Aytaç A, Yurdakul Y, kizler Ç, Olga R, Saylam A. Pumonary hydatid disease: report of 100 patients. Ann Thorac Surg 1977; 23: 145-151.

5. Kalyoncu AF, Selçuk ZT, Emri AS, Çöplü L, Sahin AA, Baris YI. Hydatidosis in Turkey. Solunum Hastaliklari 1995; 6: 1-10.(In Turkish).

6. Symbas PN, Aletras H. Hydatid disease of the lung. In: Shields TW, ed. General Thoracic Surgery, 4nd Edn. Philadelphia, PA, Williams \& Wilkins, 1994; pp. 10211031.

7. Oğuzkaya F, Akçali Y, Kahraman C, Emiroğullari N, Bilgin M, Sahin S. Unusually located hydatid cysts: intrathoracic but extrapulmonary. Ann Thorac Surg 1997; 64: 334-337.

8. Morris DL, Dykes PW, Marriner S, et al. Albendazole objective evidence of response in human hydatid disease. J Am Med Assoc 1985; 253: 2053-2057.

9. Peleg H, Best L-A, Gaitini D. Simultaneous operation for hydatid cysts of right lung and liver. J Thorac Cardiovasc Surg 1985; 90: 783-787.

10. Akhan O, Ozmen MN, Dincer A, Gocmen A, Kalyoncu F. Percutaneous treatment of pulmonary hydatid cysts. Cardiovasc Intervent Radiol 1994; 17: 271-275.

11. Dhaliwal RS, Kalkat MS. One-stage surgical procedure for bilateral lung and hydatid cysts. Ann Thorac Surg 1997; 64: 338-341.

12. Çetin G, Doğan R, Yüksel M, et al. Surgical treatment of bilateral hydatid disease of the lung via median sternotomy: experience in 60 consecutive patients. Thorac Cardiovasc Surg 1988; 36: 114-117.

13. Mottaghian H, Saidi F. Postoperative recurrence of hydatid cyst. Br J Surg 1978; 165: 237-242. 